antiquorum, with the legs incompletely striped and the shadow stripes less distinct than in burchelli. This race once inhabited Southern Angola, South-West Africa, eastwards to Southern Rhodesia and Zululand.

The last two sub-species, selousii and böhmi, are fully striped to the hooves with the shadow stripes indistinct or altogether absent. They range from the Limpopo northwards, east of the Rift Valley through Rhodesia, the Congo (Katanga and Ruanda), Nyasaland, Tanganyika, Kenya and Uganda, to Abyssinia and Somaliland.

The second group of zebras (mountain zebras) includes only one species, Equus zebra, completely striped with broad black bands. Two sub-species are recognized. Equus zebra zebra had a limited range in the mountains of the Cape Colony. Equus zebra hartmannoe is now greatly restricted, but was formerly found in South-West Africa along the sub-continuous chain of arid mountains bordering the western edge of the Namib desert. Frequently found on the seashore, it often occurred up to $7,000 \mathrm{ft}$. and was rarely seen more than thirty miles inland. It ranged from Southern Angola across the Orange River to the Kamiesberg. Both sub-species associated only in small parties.

The third group (Grevy's zebra) also includes only one species, Equus grevyi. This became known to science as late as 1882, although the Romans had zebras which may have been of this species. These zebras appear to inhabit open, sparsely-wooded country, avoiding thick bush, and are rather localized throughout Southern Abyssinia and Western Somaliland. Southwards they range into Kenya to the Tana River, westwards to Lake Rudolph and eastwards to the western border of Somaliland. They do not appear to occur farther north than lat. $8^{\circ}$. The species appears to be fairly numerous over its original range and is in no danger of extinction. Of the other two groups, one species (Equus quagga) and one sub-species (Equus b. burchelli) are extinct and another (Equus z. zebra) brought to the verge of extinction.

Being the most southerly of the zebras, Equus quagga was the first to suffer from the advance of civilization. Initially, quaggas existed in countless thousands, until the Boers began their systematic exploitation. By the first quarter of the nineteenth century the former herds of thousands had been reduced to herds of thirty to fifty animals. By 1840 they had been driven to the borders of the Cape Colony. North of the Orange River, however, they were still numerous; but exploitation for their hides continued. In addition, the farmers found the beasts a ready source of cheap meat for their native labour. The last two quaggas in the Cape Colony appear to have been shot on the Tygerberg Mountain, near Aberdeen, in 1850. Quaggas still lingered on, however, in the Orange Free State, possibly as late as 1878 .

Several times quaggas have been reported from the Krokoveld, South-West Africa, but this is almost certainly due to confusion with Hartmann's zebra.

The history of Equus b. burchelli followed a similar course. It once existed in immense herds, "but all have long ago been swept away by the rifle". Like its relative south of the Orange, this species provided a cheap supply of meat for the native labour of the progressing colonists.

The other three sub-species of Equus burchelli are still numerous; in some parts the numbers have to be kept under control to avoid damage to crops. In South-West Africa antiquorum is common and far outnumbers hartmannce. Some have adapted themselves to the mountain ranges of South-West Africa, occurring alongside but not associating with hartmannoe.

Farther to the north and east the races selousii and böhmi are still found. Where there is little cultivated land they are in no danger of reduction and in the various national parks and reserves provide one of the greatest attractions.

Equus zebra, with its two sub-species, zebra and hartmannoe, was always a more specialized animal with a very restricted range. With the quagga, the Cape race was early subjected to the onslaught of the colonists, but owing to its inaccessible habitat was not so seriously affected. As did the quagga, it provided cheap meat and leather for the farmers. By 1935 it was estimated that only a hundred were left alive. The species was then accorded complete protection; but the numbers were still reduced by poachers.

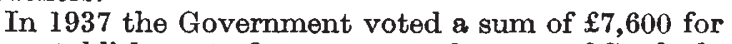
the establishment of a reserve to the west of Cradock. By 1949 the stock in the reserve was reduced to two stellions, which have since died. More recently, a new herd has been located in the Outeniqua mountains, and it was suggested that a new reserve be established there. The sum total at that time was between seventy and a hundred. In September 1950, this new reserve was opened and enriched by the generous gift of eleven animals from an African farmer. It is hoped that the future of the mountain zebra is now secure.

\section{THERMAL SWITCH FOR THE ATTAINMENT OF VERY LOW TEMPERATURES}

$\mathrm{N}$ a recent issue of the Proceedings of the Physical I Society*, workers at the Clarendon Laboratory, Oxford, described how, by an ingenious method employing a superconducting lead wire as thermal switch in a two-stage adiabatic demagnetization process in which a magnetic field of only 9,000 gauss was used, they have been able to attain an absolute temperature of approximately $0 \cdot 001^{\circ} \mathrm{K}$. and to hold the temperature of the system below $0.01^{\circ} \mathrm{K}$. for forty minutes.

In the adiabatic demagnetization method of cooling, the magnetization is usually carried out at a temperature of about $1^{\circ} \mathrm{K}$., the lowest temperature attainable by pumping liquid helium. Large watercooled magnets are required to produce the necessary field, but the use of such large fields can be avoided by using a two-stage process in which the secondstage magnetization is effected at the lower temperature, less than $1^{\circ}$ K., reached by the first-stage demagnetization. It is necessary, however, to have a means of making and breaking the thermal contact between the two stages. E. Mendoza, in 1948, used a piece of copper foil which was broken mechanically after magnetization of the second stage, but his apparatus suffered from very rapid reheating of the second stage.

The Oxford method is to use two cylinders of compressed salt, the upper and larger of iron ammonium alum, and the lower a dilute mixture of erystals of potassium aluminium alum and potassium chrome alum, as the two stages, connected by a lead wire

* Darby, J., et al., Proc. Phys. Soc., A, 64, 861 (1951). 
of the highest purity and about $3 \mathrm{~cm}$. long. This wire is the thermal switch between the two stages. With both stages magnetized, thermally isolated from the surroundings and at $1^{\circ} \mathrm{K}$., the magnet was lowered slowly so that the upper stage was de magnetized while the lower stage remained in the field. The lead wire, being still in a field greater than its threshold value, remained a good thermal conductor, and heat was transferred from the lower to the upper stage. With the magnet lowered still further so that only the lower stage was in the field and any stray field around the lead wire carefully reduced to zero, the lower stage was more or less thermally isolated from the upper, because the lead wire was superconducting and thus of considerably reduced thermal conductivity. Removal of the magnet demagnetized the lower salt and the temperature fell to the order of $0.001^{\circ} \mathrm{K}$. The residual heat inflow of the apparatus after demagnetization is stated to be about $1 \mathrm{erg} / \mathrm{min}$.

The possibility of adapting the superconducting switch to control the flow of heat between the nuclear and electronic stages in the proposed combined use of nuclear and electron paramagnetism, so as to extend the lower limit of temperature attainable, is also briefly discussed in the article.

\section{REPRODUCTION OF THE TUBERCLE BACILLUS}

A COLLOQUIUM upon "Reproduction of the Tubercle Bacillus" was held in Cambridge on December 8, 1951, at the Cavendish Laboratory, continuing in the afternoon at the Strangeways Laboratory. The meeting was sponsored by Dr. E. M. Brieger, of Papworth Hospital, near Cambridge.

The introductory address was given by Dr. K. A. Bisset, who stressed the complexity of structure of the organism and of its modes of reproduction. These appearances are often unrecognized, because of the practice of examining only well-grown cultures, and then almost exclusively by means of techniques which reveal only acid-fast stages. Dr. Bisset also suggested that it is important to try to make certain to which of the many known types of growth and reproductive activity a particular phenomenon belongs before attempting to complete its interpretation.

The relationships between mycobacteria and other Actinomycetes was indicated by E. O. Morris, who showed that many of the complex reproductive processes described in $M$. tuberculosis are quite commonly found in these apparently allied forms. $\mathrm{He}$ especially emphasized germination of the resting stages by means of germ tubes as characteristic of the entire group.

Dr. V. E. Cosslett demonstrated the work, which had been performed in collaboration with Dr. Brieger and Miss A. M. Glauert, upon the electron microscopy of various stages in the life-history of $M$. tuberculosis. Early cultures of an avian strain consisted ishort rods which, after forty-eight hours, began to be replaced by larger, beaded filaments, and were again restored, in the later stages of culture, to the original form. Granular forms of bovine bacilli isolated from infected rabbit tissues were also examined. The larger granules, $0 \cdot 5-1 \mu$ in diameter, appeared to contain rod-like bacterial elements; this material proved to be highly infectious to guinea pigs.
A substantial degree of correlation between the interpretation of electron, phase-contrast and classical mioroscopy seems now to have been achieved, although the density of the putative structures, and especially of the nucleus, to the electron beam appears to vary, both relatively and absolutely, at different stages of growth. It was also pointed out, by Dr. Bisset and Mr. Morris, that many structures, especially septa and cross-walls, can be demonstrated only irregularly by the electron microscope, but are regular features of the organism as seen in stained preparations. Dr. Cosslett agreed.

Dr. C. H. Lack described some of the appearances which can be seen in synovial fluid from tuberculous joints. Acid-fast and non-acid-fast granules were seen. Slide cultures, examined stained and by phasecontrast microscopy, showed many of the forms reported in life-cycle studies by earlier workers, including 'cocci' and tetrads. 'Cocci' were observed to germinate. A syncytial stage was also observed, in which numerous nuclei were embedded in a sheet of cytoplasm. The granular forms infected guinea pigs only exceptionally, and the coccal and syncytial stages from culture gave no allergic response and were apparently non-infective, but produced splenic enlargement and marked wasting.

In the afternoon Dr. E. M. Brieger and Miss A. M. Glauert showed a series of lantern slides of their preparations of growing cultures of different types of $M$. tuberculosis. Dr. Brieger demonstrated that by the use of nigrosin as a counter-stain, the derivation of acid-fast colonies from non-acid-fast mycelial structures could be followed in avian strains. Mr. Morris commented upon the possibility that these represented primary and secondary mycelia, as in Actinomycetes and Streptomyces. Miss Glauert described similar results obtained using the phasecontrast microscope to study living cultures of avian bacilli, growing on embryo-extract-chick-plasma clots. Two main types of micro-colony were seen developing from mycelia: serpentine 'cords' of bacilli, and irregular, spherical 'hedgehogs'. Both types eventually became acid-fast although they developed from mycelia which were mainly non-acid-fast. Dr. Brieger also reported that somewhat similar results had been obtained with a bovine strain which had been injected into the intra-amniotic fluid of the egg. In response to a query, he stated that he had not separated these types and consequently had not attempted to isolate a cord factor, although the strain was highly virulent.

Reference was made by Dr. Honor B. Fell to previous warm-stage observations of living avian bacilli, when the drawings made during continuous observation of the same field showed the peculiarities of the two types of development, the bacillary and the mycelial type.

Dr. E. Klieneberger-Nobel was requested to give her views upon the relationship between the $L$-form in other bacteria and the granular symplasms of M. tuberculosis. She gave an account of the phenomenon in various bacteria, and emphasized that it frequently appeared as a reaction to an unfavourable environment.

There was much general discussion, in an informal atmosphere. An impression was achieved that much had been done to correlate the views of workers in the physical, biological and medical fields of this problem, and that the area of agreement was both surprisingly and satisfactorily wide. 